\title{
Real World: Empowering Representations of Women through Film
}

\author{
Tessa Lewin
}

Abstract This article makes an argument for the added value of the use of documentary film in development research communication. It draws broadly on the specific experience of the Real World film scheme developed by the Pathways of Women's Empowerment Research Programme Consortium and Creative England, to create empowering representations of women. It argues that both researchers and film-makers have much to gain by collaborating on the political project of co-crafting a visual argument, to create a nuanced and emotive end product.

\section{Introduction}

In many countries, the cultural underpinnings of gender inequality and discrimination against women are reinforced through media (GMMP 2010).

\section{Does art enhance our lives or distract us from it... fantasy vs realism... The superhero is escapist, The DREAM. Clearly a distraction. But the other is its own abstraction - distilling life to its most mundane, suppressing the dream with CYNICISM. Gabriel Ba and Fabio Moon dance between both, infusing reality with the sacred (Thompson 2011).}

We are living in very exciting times in terms of the possibilities that exist for creatively linking research with other areas of expression; for employing multiple strategies to interrupt, question, expand and re-present existing orthodoxies. While not wanting to glorify film above other forms of media, it is, like other visual or audio forms, an immediate medium, and an emotive one. Films tell stories, they reach out, and they can very quickly give us a nuanced sense of context. This article tells the story of a documentary film scheme called Real World that was established to enlist professional filmmakers to tell research stories, to describe, provoke and inspire change; to try to shift the horizons of the possible.
The Pathways of Women's Empowerment Research Programme Consortium (RPC, hereafter 'Pathways') was a change-oriented international consortium of feminist activist researchers and communicators, brought together through a five-year project from 2006-11. 'Its aim is to bring fresh empirical and conceptual insights to an audience of development academics and policy actors, for whom 'women's empowerment' may be a familiar mantra, but one rarely accompanied by a consideration of the complexities of change or the lived realities of women's lives' (Cornwall and Edwards 2010: 1). Now that our initial project phase has ended, Pathways is currently in the process of morphing into a network.

\section{Real World}

In 2007, with Screen South (the Regional Screen Agency for the South East of England), Pathways set up the 'Real World' film scheme. The scheme aimed to link early-career film directors from Screen South's geographical region with our researchers in South Asia, the Middle East, West Africa and Latin America, to produce a series of documentary films that positively re-presented women in these contexts.

Screen South was keen to add both an international, and a social justice dimension to the films that they were producing. The UK 
'supplies' directors to platforms such as the BBC, and $\mathrm{Al}$ Jazeera, that have a broad global reach, and we were excited about the opportunity to engage with some of these directors, and enlist them in helping to challenge the fairly limited representations of development, and in particular of women, that we saw being broadcast.

Of course film-makers have always worked with academics. They bring them in as 'expert witnesses' to give evidence that supports their narrative arguments. Development practitioners and academics too, often commission film-makers to make films for them. What Real World tried to do was to make films that were led by the research, so the Pathways researchers were shaping the narrative content, but the film-makers were controlling the shape of the story, and visual structure. Development activist-academics and film-makers were working together to try and articulate new visual arguments.

Through the life of the scheme so far, we have produced 12 films. Four of the three-minute shorts (A Vida Politica) were shot in Brazil and look at diverse forms of social activism through four women - a hairdresser, a model, a performance artist, and a politician. Another four (Thorns and Silk), produced the same year, depict four women in Palestine engaged in jobs that are traditionally regarded as 'men's work'. There is a set of three films, of varying length (30", 3' and 33'), looking at Mulki Al-Sharmani's research on $\mathrm{Khul}$, an Islamic legal reform that offers women access to a no-fault divorce in exchange for the forfeit of their right to any financial claim. The final film 30 per cent is shot in Sierra Leone, and examines women's participation in formal politics in Sierra Leone, in particular the push for the passing of the ' 30 per cent bill' which would introduce a parliamentary quota for women. This film uses a mixture of live action and animation, and is stylistically the most creatively daring. We were very excited about using the animation to push beyond the imaginative boundaries of traditional political documentary, and to allow the audience to inhabit both the material and psychological landscapes of the women involved.

\section{Media context}

Many social commentators have noted the rise of the visual, or our 'visual turn' (Spencer 2011: 35). Visual images are ubiquitous and the public understanding of, and reading of, these images is increasingly sophisticated. These films were part of an acknowledgement that popular culture is an increasingly significant 'player' in public engagement with research, and that visual arguments are often both more accessible and more compelling than written academic texts.

Many social movements have been accompanied by a burst of public artistic production. Visual art as a form of social protest and engagement, as a new language of politics, seems to be experiencing a boom (Hallez, this IDS Bulletin). Hand-in-hand with this visual boom has been a revolution in digital technology. The explosion of social networking, the ubiquity of affordable digital technology that allows people to document, capture and create visual imagery, and the multitude of ways people are accessing and engaging with both information and other people online is unprecedented (Moglen 2011; Brooke 2011; Mason 2012).

Film is a key form of documentation and expression in this new, networked environment (WITNESS 2011). The speed with which the Kony 2012 film spread online (reaching 76 million people in nine days) gives some sense of the potential of using online technologies to engage and influence (Webb 2012).

The digital explosion, and the fact that people have become more used to, and want visual content on account of this, is both an opportunity to engage, and a push to produce better quality materials to capture peoples' attention. As the amount of possible material expands, and peoples' attention spans shrink, the quality and style of work required to influence public opinion changes. Films, once produced, take on a 'social life' of their own and often travel to unexpected audiences.

Weiss (1977) and Hovland (2003) both point out the gradual and indirect impact that research can have. Particularly in framing how we see the world and the concepts we use to understand it. The use of film in research offers an important tool for influencing these framings.

According to a recent survey, 'Members of the UK public widely associate developing countries with disasters. Indeed, aside from perceptions of corrupt leaders, the images that spring to mind when they think of poor parts of the world are of 
war, earthquakes and famine' (IDS 2012). Kamerick (2012) talks about the importance of women as media producers if we are to get a more complete picture of the world.

\section{Gender representation}

The predominant image evoked by international development agencies when they talk of empowerment is of women gaining the (material) means to empower themselves as individuals, and putting this to the service of their families and communities. This tends to neglect what women are doing for and by themselves to bring about change in their own and other women's lives (Cornwall and Edwards 2010).

Binyavanga Wainaina (2005), in a much quoted article for Granta magazine 'How to Write about Africa' satires the stereotypes in writing about Africa:

Among your characters you must always include The Starving African, who wanders the refugee camp nearly naked, and waits for the benevolence of the West. Her children have flies on their eyelids and potbellies, and her breasts are flat and empty. She must look utterly helpless. She can have no past, no history; such diversions ruin the dramatic moment. Moans are good. She must never say anything about herself in the dialogue except to speak of her (unspeakable) suffering. Also be sure to include a warm and motherly woman who has a rolling laugh and who is concerned for your wellbeing. Just call her Mama. Her children are all delinquent.

We are all familiar with these stereotypes - the victim, the Madonna. Cornwall (2005) writes about the two discursive strands that run through the literature on gender in sub-Saharan Africa the 'voiceless victim' and the 'self-reliant heroine'. Reeves (1997) writes about the discursive othering of 'Third World Women' in non-governmental organisation (NGO) advertising imagery; of the emotive appeal to the potential donor which allows them to entertain rescue fantasies. Part of the rationale behind this film scheme was to influence a new generation of film-makers, and to try and change their development representations.

Real World was an attempt to move away from 'rescue narratives', and break, challenge, complicate and expand the menu of existing stereotypes of women. We hoped the films would document everyday lived experience and create images that move beyond women as statistic, as mono-dimensional stereotype to show nuance, plurality, complexity, and contradiction.

\section{Democratising research}

Bell Hooks (1994) writes passionately about academics' responsibility to popularise their research, to take it out of and beyond the academy. For researchers with a strong interest in social change, proactively doing so is a moral imperative. Al-Sharmani (2010) has argued eloquently (in relation to legal reforms to marriage in Egypt) that legal reform is not enough to address the problems that women suffer from. 'I think we need to do more. We really need to address public opinion, how men and women think about women's roles and relations [within marriage]. We need to have a dialogue, a societal dialogue.' Film offers one of many ways to provoke and inspire 'indirect' change, foster societal dialogue and expand engagement with research.

Visual methods are particularly relevant for social change, beyond the forms of knowledge they can elicit and communicate because they have significant transformative potential both in terms of their process, and the products that emerge through this process. Duncombe (2007) argues that good empirical research; intellectual work, and compelling arguments are not enough to provoke change. He suggests people need to see alternative realities. He argues we need to actively seek to visualise utopian alternatives. In other words, visual representations can take us beyond our existing engagement with the everyday, the mundane. 'The entertainment state should be ruthlessly criticised, but the techniques used to create and maintain it need to be enthusiastically exploited for their progressive potential' (Duncombe 2007: 14). He argues for the importance of spectacle in performing and amplifying reality.

Cornwall (interview, May 2012) talks about the importance of making something aesthetically beautiful because of its capacity to transport you, to enable you to suspend your disbelief. 'When a film is badly constructed and shot, you notice that it's been constructed. You start criticising it. When it's seamless, you become immersed in it.' 


\section{Film as embodied}

This sense of complete immersion evoked by film is an important part of its power. Visual material provides a form of 'thick description' (Geertz in Spencer 2011:33). Spencer argues that the multi-sensory impact of the visual affects us emotionally before our sense-making apparatus is able to process our reaction (Spencer 2011:32). This multilayeredness, or 'thickness', that the visual offers, and the way it physically locates the viewer, is part of what accounts for its impact.

Mitchell (2011) talks about the capacity for images to 'haunt', to stay with you. Cornwall similarly talks about the almost visceral nature of film:

[Film is] such a powerful medium to convey representations and to change, to mess, with representations. In three minutes you can say something far more complex and deeply layered and provocative to get people engaged, much more than an academic piece of writing. Because it touches on peoples'feelings, puts people into a scene, gets them challenging their viewpoints (Andrea Cornwall, interview, May 2012).

Film places the viewer inside the scene; it conveys a sense of place (Rose 2007; Mitchell 2011; Spencer 2011). The emotive and embodied nature of film are both particularly important in a development industry that so often lacks both a sense of 'real' individuals and specific context. What you can get with film is very personal, very local knowledge.

\section{The importance of story}

We spend a phenomenal amount of our lives following stories: telling them; listening to them; reading them; watching them being acted out on the television screen or in films or on stage. They are far and away one of the most important features of our everyday existence (Booker 2004).

Melkote (2000: 44) notes that stories can exercise power 'by influencing or shaping the shared consciousness of a people'. Colleagues in Cairo, collectively known as Ana el-Hekkeya [So She Said], have tried to shift popular representations of women through the use of storytelling. They argue that in the Arab world, most locally produced cultural materials such as literature, media and cinema productions, display gender discrimination that disempower women and limit their potential roles in their private and public lives. The scarcity, or sometimes absence, of cultural materials providing more positive images of women accentuates the subordination and marginalisation of women, which becomes internalised and adopted by new generations (Ali 2010).

Their work articulates much of the ethos behind the Real World scheme. An important constraining or structuring element of film is the story. What good film-makers do well is find, and tell, stories. Part of what we learnt through making these films, was that many researchers and academics are not particularly good at either identifying, or telling good stories.

The way in which each set of films was conceived, and executed, varied significantly. During the first year of the scheme when the Palestinian and Brazilian films were made we put forward (as part of the callout for film-makers) a longlist of potential topics for films, based on which of the numerous Pathways research projects we thought had good 'story potential'. We asked film-makers to respond to this list with a proposed treatment, which formed the initial basis of our selection process. We discovered that unless the project had a 'film champion' who was prepared to work actively with the film-maker in developing their ideas for the film, explaining the political significance and the nuances of their research, the films were very difficult to make.

We discovered also that the concerns we had about representations of both women and development were very much present in the applications we received for the scheme, and in negotiations during the selection process. One film-maker initially submitted a treatment that Pathways researchers found extremely problematic and victimising. The storyline traced an oppressed women being saved, or turning her life around. For her, the black and white victim/hero narrative arc made the best 'easy' story, engaging, sensationalist and simple. Many of our colleagues on the selection panel for the scheme were not concerned by the proposal content at all, as they were convinced that the candidate was an excellent film-maker. Her politics, for them, were secondary. Having set up an 'industry' panel to ensure in many ways that we did not end up with an 'academic' film, we found ourselves in one of many difficult situations. 
The film-maker mentioned above did become part of the scheme, and is still working with us today. She proved to be an excellent film-maker but also, fortunately for us, had a combination of emotional intelligence and humility that made her very open to engaging with, and embracing some of the ideas of the Pathways researchers. Through the process of her engagement with the Real World scheme, and through dialogue with local academics and activists she was, as she puts it, 're-educated' and realised there were other, more nuanced interesting ways of telling a story.

I think I personally began to analyse the way that women's images and ideas were being conveyed to audiences. I learnt a lot about feminism and the ways to perceive issues of 'choice' and 'rights'. The idea for the films really came from meeting the activists that were leading their own movements towards selfempowerment (Kat Mansoor, film-maker and Real World director).

One of our researchers equally struggled with the film-making process; she observed:

Half the time I'm telling her about research and she's not interested because it's not a story... [and later] For me, as an academic, the process of thinking there are a load of really complex issues, and my wanting to tell the complexities and nuances of it in an academic way isn't going to reach your general public audience. They need to have something that grabs them, that's a story, that's simple - you can have some complexity but it needs to be simple to grasp. It's changed my writing. It's changed what I'm putting energy into. It's made me realise how totally out of touch I was with what would make a good story. Because I'm an anthropologist, my writing has always had stories in it, it's always been about stories, that's what anthropologists do, but I think I've been much less focused about trying to communicate something through that story (Andrea Cornwall, interview, May 2012).

Out of this initially fractious collaboration has emerged a strong solidarity between the filmmaker and the researcher that has added immense value to each of their work.

\section{Provoking questions}

Because of the subjective nature of interpreting a film, there is always a risk that a viewer's reading may reinforce their stereotypes, or harden their views, or not invite questioning.
This risk is another reason why researchers can be wary of engaging in working with filmmakers. Films, like other visual media, invite the viewer to complete their meaning. Images pose questions rather than presenting answers (Allmark in Spencer: 2011:34). They question rather than confirm.

\section{As a film-maker you may not want to trade in arguments, you may want people to come away with a set of feelings and perceptions of things that they have to do some work to resolve. You can't take them all the way along the road otherwise it's not interesting. In an academic piece of writing you have to take people all the way down the road. If there are things missing in your argument, then your argument is not persuasive. It's that linear-rational thing. There's something about the incompleteness of film, which is really important (Andrea Cornwall, interview, May 2012).}

Of course making oneself vulnerable as a researcher to all these potential hazards is exacerbated when a film-maker is not only from another disciplinary world, but also from an entirely different culture. Real World put 'Northern' documentary directors together with 'Southern' producers and academics. The topic of the films, and indeed much of their content, was determined by Southern research agendas and, not surprisingly, numerous tensions emerged through negotiating the development of the films. Often Pathways researchers were already extremely busy, and the idea of being involved in supporting a film was difficult. Many of them did not understand the process, and found it daunting, many felt that their research was not 'film-worthy', or couldn't imagine how it might be. Some did not want the responsibility of 'babysitting' foreign film-makers. Some did not feel that their own research had progressed far enough to be the subject of a film. Some felt strongly that local film-makers were better placed to do the work. On one occasion a change in government meant that a production had to be cancelled at the last minute because people were nervous about foreign people with cameras coming in. On another occasion the film-maker chose a story that the researcher was not happy with, and they negotiated a change.

Despite all these problems, there were some elements of the insider/outsider dynamic that worked for both the researchers and the film- 
makers involved in the Real World scheme. For the researchers, having a mirror to reflect back at them what was being understood about their work, not by fellow academics, but by filmmakers, with all the naïve questions that outsiders ask, and their capacity to 'make strange' again an overly familiar context was extremely valuable.

For the film-makers, the scheme offered an immersive experience, with many unexpected challenges.

We spent every night backing up our files. Often there was no electricity, and we had no chance to reinterview people. If you arrived late because of traffic and it was dark. It was dark [sic]. There was never a quiet place to work, because of traffic, or generators. Our equipment had to fit into our handbags for safety. As you will see there are very few shots that are not taken either in a car or inside someone's house (Anna Cady, Real World director, interview, April 2012).

These logistical constraints both challenged their creativity, and also gave them invaluable insight into the everyday lives of the people with whom they were working.

\section{Conclusion}

Perhaps the most profound lessons from the scheme have been, firstly, the importance of the brokering role played by people who have an in-depth understanding of both the research context and the film-making process. And secondly, that the creative tension between academic thinking and film-maker thinking can

\section{References}

Ali, Mona (2010) Talking on Empowerment, www.youtube.com/watch?v=tjp4YbcJpRs (accessed 2 July 2012)

Al-Sharmani, M. (2010) in L. Bennet, Khul, Brighton: Real World Films, www.youtube.com/ watch? $=$ aL7pwU_Ml5k (accessed 2 July 2012)

Booker, C. (2004) The Seven Basic Plots: Why We Tell Stories, London: Continuum

Brooke, H. (2011) The Revolution will be Digitalised: Dispatches from the Information War, London: Heinemann

Cornwall, A. (ed.) (2005) Readings in Gender in Africa, Oxford: James Currey

Cornwall, A. and Edwards, J. (2010) 'Negotiating Empowerment', IDS Bulletin 41.2, Brighton: IDS (in the right circumstances, and with a lot of effort on both sides) make for both a process and a product that has moments of magic, and is hugely rewarding.

Where academics are strong on theory, good at adding complexity and nuance, film-makers tend to be concerned with personal journeys, with making things simple and clear. Leadbeater (2009), among others, has written about the benefits of cross-disciplinary working. He cites an experiment in complex systems at the University of Michigan which found that

groups with diverse skills and outlooks came up with smart solutions more often than groups of very clever people who shared the same outlook and skills. Groups made up of many people who think in different ways can trump groups of people who are very bright but alike (Leadbeater 2009: 72).

Academics are often in a very privileged position in terms of the access they have to people, to activists, to communities. Film-makers are experts in crafting stories, in shaping representations, but rarely have the luxury of the same level and longevity of engagement afforded to academics. Researchers and film-makers have much to gain by collaborating on the political project of co-crafting a visual argument. We know representations matter; they reinforce social relations. Empowerment is not just about having choices, but about shaping the choices you have. Film has huge potential to shift the boundaries of what's considered possible, and articulate new alternatives.

Duncombe, S. (2007) Dream: Re-imagining Progressive Politics in an Age of Fantasy, New York: The New Press

GMMP (Global Media Monitoring Project) (2010) Who Makes the News, Toronto: World Association for Christian Communication

Hooks, B. (1994) Outlaw Culture, New York: Routledge

Hovland, I. (2003) Communication of Research for Poverty Reduction: A Literature Review, ODI Working Paper 227, London: Overseas Development Institute

IDS (2012) www.ids.ac.uk/news/ids-filmexamines-how-british-media-portray-globalsouth (accessed 2 July 2012) 
Kamerick, M. (2012) www.ted.com/talks/lang/en/ megan_kamerick_women_should_represent women_in_media.html (accessed 2 July 2012)

Leadbeater, $\overline{\mathrm{C}}$. (2009) We -Think: Mass Innovation, not Mass Production, London: Profile Books

Mason, P. (2012) Why it's Kicking Off Everywhere: The New Global Revolutions, London: Verso

Melkote, S. (2000) 'Reinventing Development Support Communication to Account for Power and Control in Development', in Gwim Wilkins, K. (ed.), Redeveloping Communication for Social Change, Maryland: Rowman and Littlefield Publishers, Inc.

Mitchell, Claudia (2011) Doing Visual Research, London: Sage

Moglen, E. (2011) 'Liberation by Software', The Guardian, 24 February, www.guardian.co.uk/ commentisfree/cifamerica/2011/feb/24/ internet-freedomofinformation (accessed 21 March 2011)

Reeves, H. (1997) 'The Discursive Othering of Third World Women in NGO Advertising
Imagery', MSc dissertation, London School of Economics and Politics

Rose, Gillian (2007) Visual Methodologies, London: Sage

Spencer, Stephen (2011) Visual Research Methods in the Social Sciences, London: Routledge

Thompson, C. (2011) 'Introduction', in Fábio Moon and Gabriel Bá, Daytripper, New York: Vertigo

Wainaina, B. (2005) 'How to Write about Africa', Granta 92: The View from Africa, London: Granta Publications

Webb, M. (2012) http://blogs.aljazeera.net/blog/ africa/ugandans-react-anger-kony-video (accessed 2 July 2012)

Weiss, C. (1977) 'Research for Policy's Sake: The Enlightenment Function of Social Research', Policy Analysis 3.4: 45-51

WITNESS (2011) Cameras Everywhere: Current Challenges and Opportunities at the Intersection of Human Rights, Video and Technology, Brooklyn NY: WITNESS 